\title{
Comparative studies of aerobic and anaerobic biodegradation of methylparaben and propylparaben in activated sludge
}

\author{
Yang $\mathrm{Wu}^{\mathrm{a}, \mathrm{b}, *}$, Qian Sun ${ }^{\mathrm{b}}$, Yu-wen Wang ${ }^{\mathrm{b}}$, Cheng-xun Deng ${ }^{\mathrm{a}}$, Chang-Ping Yu ${ }^{\mathrm{b}, \mathrm{c}, * *}$ \\ a Department of Biology and Environmental Engineering, Hefei University, Hefei 230061, China \\ b CAS Key Laboratory of Urban Pollutant Conversion, Institute of Urban Environment, Chinese Academy of Sciences, Xiamen 361021, China \\ ${ }^{\mathrm{c}}$ Graduate Institute of Environmental Engineering, National Taiwan University, Taipei 106, Taiwan
}

\section{A R T I C L E I N F O}

\section{Keywords:}

Methylparaben

Propylparaben

Activated Sludge

Biodegradation

Benzoic acid

\begin{abstract}
A B S T R A C T
The biodegradability of two typical parabens (methylparaben and propylparaben) in activated sludge, at initial concentrations of $1 \mathrm{mg} \mathrm{L}^{-1}$ or $10 \mathrm{mg} \mathrm{L}^{-1}$, was investigated under aerobic and anaerobic conditions. The results showed that microorganisms played a key role in degradation of parabens in WWTPs, especially in aerobic systems. The half-lives of methylparaben and propylparaben under aerobic conditions have been estimated to range between 15.8 and $19.8 \mathrm{~min}$, and benzoic acid was found to be one of the major biodegradation products. The calculated biodegradation efficiency of methylparaben and propylparaben in activated sludge under aerobic conditions was significantly higher than that observed under anaerobic (nitrate, sulfate, and Fe (III) reducing) conditions, as methylparaben and propylparaben exhibited comparatively higher persistence in anaerobic systems, with half-lives $\geq 43.3 \mathrm{~h}$ and $\geq 8.6 \mathrm{~h}$, respectively. Overall, the results of this study imply that the majority of these parabens can be eliminated by aerobic biodegradation during conventional wastewater treatment processes, whereas minor removal is possible in anaerobic systems if an insufficient hydraulic retention time was maintained.
\end{abstract}

\section{Introduction}

Parabens, which are esters of $p$-hydroxybenzoic acid, have frequently been used as preservatives in food, cosmetics and pharmaceuticals since the mid-1920s (Andersen, 2008; Ma et al., 2016; Błędzka et al., 2014). Common esters include methyl-, ethyl-, propyl-, butyl-, and benzyl- parabens. Parabens have long been considered safe preservatives because of their good antimicrobial properties, low cost, low toxicity, and high stability (Błędzka et al., 2014; Haman et al., 2015; Andersen, 2008). However, recent studies have shown that parabens might possess endocrine disrupting effects and be associated with breast tumors in women and sperm DNA damage (Darbre and Charles, 2010; Meeker et al., 2011). Since parabens have the potential to harm human health, investigation of their occurrence, exposure, toxicity and removal from different environmental matrices has received global attention (Albero et al., 2012; Wu et al., 2016; Evgenidou et al., 2015; Xue et al., 2015; Schlumpf et al., 2010; Gorga et al., 2015; Liao et al., 2013; Petala et al., 2015). These substances are mainly discharged into the environment through urban sewage, and studies conducted to date have shown that trace concentrations of parabens and their halogenated by-products are ubiquitous in the aqueous phase and sewage sludge of WWTPs (Wang and Kannan, 2016; Matamoros et al., 2016; Canosa et al., 2006; Li et al., 2015; Sun et al., 2016).

Methylparaben (MP) and propylparaben (PP), which are the most commonly used parabens, have been detected in different environmental matrices with high frequency. Wang et al. (2013) found the median concentration of urinary parabens measured for Chinese adults was $33.2 \mathrm{ng} \mathrm{mL}^{-1}$. Notably, $1000-10,000 \mathrm{ng} \mathrm{mL}^{-1}$ of parabens were found in urine from some Chinese adult females. They also indicated that parabens were present predominantly ( $>90 \%$ ) as conjugated species in urine, especially, MP and PP were the predominant compounds. A significant positive correlation was found between the concentrations of MP and PP in urine samples. In order to further investigate the sources of Chinese exposure to parabens, Guo et al. (2014) measured concentrations of six parabens in five categories of personal care products $(\mathrm{N}=52)$ collected from Tianjin, China, and estimated human exposure doses to these compounds. Their study showed that hand and body lotions were the major contributors to exposures, and the daily exposure doses for MP, and PP from these products were 10,200 and $4890 \mu \mathrm{g}$, respectively.

Widespread use of personal care products can make parabens leaking into aquatic environment, mainly through wastewater treat-

\footnotetext{
* Corresponding author at: Department of Biology and Environmental Engineering, Hefei University, Hefei 230061, China.

** Corresponding author at: CAS Key Laboratory of Urban Pollutant Conversion, Institute of Urban Environment, Chinese Academy of Sciences, Xiamen 361021, China.

E-mail addresses: yangwu@iue.ac.cn (Y. Wu), cpyu@iue.ac.cn (C.-P. Yu).
} 
ment discharges. Molins-Delgado et al. (2016) determined the occurrence of MP and PP in influent and effluent wastewater from the 19 major WWTPS of Catalonia, Spain. A significant positive correlation also was observed for those parabens in their study, strongly indicating a similar source of pollution. Although parabens are expected to be eliminated using conventional biological treatment, they are ubiquitous in effluent of WWTPs. Matamoros et al. (2016) assessed the seasonal performance of four different full-scale wastewater technologies on elimination of emerging contaminants, including MP. They found that the highest removal efficiency was only $89 \pm 3 \%$ during the warm season when waste stabilization pond technology was employed. Notably, the MP removal efficiency of the other three technologies investigated, namely, an extended aeration system, rotating biological contactor and constructed wetland, was significantly lower than previously reported (Madsen et al., 2001; Hernández Leal et al., 2010; Li et al., 2015). Madsen et al. (2001) reported that MP and PP are readily biodegraded under aerobic conditions, with biodegradability (biological oxygen demand) of about $90 \%$ of the theoretical oxygen demand. Li et al. (2015) also indicated that biodegradation led to significant elimination of parabens during conventional wastewater treatment. However, they deduced that parabens were mainly degraded in the anaerobic tank based on mass balance results, which is in accordance with the results reported by Yu et al. (2011), who found that levels of parabens decreased significantly during anaerobic processes.

Given this background, microbial biodegradation is considered as an important environmental mechanism of parabens removal when they are discharged into wastewater treatment plants (WWTPs). Accordingly, it is necessary to investigate differences in the aerobic and anaerobic biodegradation of parabens. Therefore, in this study, the biodegradation of different levels of MP and PP in activated sludge collected from a WWTP in Xiamen, China, were investigated. The kinetics of the indigenous microbes-initiated oxidation of MP and PP under different redox conditions was systematically compared, as well as their possible transformation products. These experimental and theoretical data will be useful for further interpretation of the mechanism of parabens biodegradation in WWTPs.

\section{Materials and methods}

\subsection{Chemicals}

Methylparaben (methyl 4-hydroxybenzoate, $\mathrm{C}_{8} \mathrm{H}_{8} \mathrm{O}_{3}$, MP) and propylparaben (propyl 4-hydroxybenzoate, $\mathrm{C}_{10} \mathrm{H}_{12} \mathrm{O}_{3}$, PP) with purities above 99\% were purchased from Acros Organics. The molecular structures and chemical properties of MP and PP are listed in Table 1 (http://www.drugbank.ca, http://www.chemspider.com). All organic solvents were of HPLC grade and purchased from Tedia Co. (Fairfield, Ohio, USA). Conical flasks were deep cleaned with detergent and Milli$\mathrm{Q}$ water, then baked at $400{ }^{\circ} \mathrm{C}$ prior to use. Stock solutions of MP and PP were prepared in methanol and stored at $-20^{\circ} \mathrm{C}$.

\subsection{Sample collection}

Grab samples of return activated sludge were collected on July 24, 2015 from a municipal WWTP in Xiamen, China. This WWTP is equipped with a primary treatment tank, an Orbal oxidation ditch and UV disinfection before effluent discharge. The mixed samples were collected in amber bottles and transported to the laboratory immediately for preliminary incubation under aerobic and anaerobic conditions.

\subsection{Biodegradation experiments}

Biodegradation experiments were conducted in duplicate individually under different redox conditions. Prior to spiking with parabens, the activated sludge was pre-incubated for one week under aerobic and anaerobic conditions. Incubation medium with $10 \%$ activated sludge (v/v, MLSS:6910 $\mathrm{mg} \mathrm{L}^{-1}$ ) was prepared in minimum mineral salt (MMS) containing peptone $\left(32 \mathrm{~g} \mathrm{~L}^{-1}\right)$, yeast extract $\left(22 \mathrm{~g} \mathrm{~L}^{-1}\right)$, urea $\left(6 \mathrm{~g} \mathrm{~L}^{-1}\right), \quad \mathrm{NaCl}\left(1.8 \mathrm{~g} \mathrm{~L}^{-1}\right), \mathrm{CaCl}_{2} \cdot 2 \mathrm{H}_{2} \mathrm{O}\left(0.8 \mathrm{~g} \mathrm{~L}^{-1}\right), \mathrm{MgSO}_{4} \cdot 7 \mathrm{H}_{2} \mathrm{O}$ $\left(0.4 \mathrm{~g} \mathrm{~L}^{-1}\right), \mathrm{K}_{2} \mathrm{HPO}_{4}\left(55.6 \mathrm{~g} \mathrm{~L}^{-1}\right), \mathrm{KH}_{2} \mathrm{PO}_{4}\left(16 \mathrm{~g} \mathrm{~L}^{-1}\right)$ (Lozada et al., 2004) and amended with trace vitamins (Yang and McCarty, 1998; Liu et al., 2011). For anaerobic treatment, the incubation media was purged with nitrogen to deoxygenate. Sterile controls containing the individual compounds were also analyzed to establish variations in concentration changes and verify that any hydrolysis metabolites formed were detected during the experiment. Prior to this study, our research group detected the concentrations of various types of PPCPs in the influent and sludge of the studied WWTP, which included MP and PP. The background concentration in sludge ranged from $1.0 \pm 0.6$ to $6.8 \pm$ $0.9 \mu \mathrm{kg}^{-1}$, while the average concentration of MP and PP in the influent was $247.4 \mathrm{ng} \mathrm{L}^{-1}$ and $311.3 \mathrm{ng} \mathrm{L}^{-1}$, respectively (data not shown).

For sterile control samples, the conical flasks with incubation media were autoclaved $\left(120^{\circ} \mathrm{C}, 20 \mathrm{~min}\right)$ for three consecutive days. The halflife of MP and PP degradation was calculated based on the first-order equation as follows:

Table 1

CAS NO., molecular structure, pKa, $\log K o w, \log K o c$ of the target compounds.

\begin{tabular}{|c|c|c|c|c|c|}
\hline Compounds & CAS No. & Structure & $\mathrm{p} K \mathrm{a}^{\mathrm{a}}$ & $\log k_{\mathrm{ow}}{ }^{\mathrm{b}}$ & $\log K_{\mathrm{oc}}$ \\
\hline Methylparaben (MP) & $99-76-3$ & & 8.3 & 1.9 & 2.1 \\
\hline Propylparaben (PP) & $94-13-3$ & & n.a & 3.0 & 2.6 \\
\hline
\end{tabular}

\footnotetext{
n.a. - Not available.

a http://www.drugbank.ca/.
}

b http://www.chemspider.com. 
Table 2

Gradient of mobile phase for HPLC analysis of MP and PP.

\begin{tabular}{llllll}
\hline Eluent & 0 min & 2 min & 5 min & 7 min & $14 \min$ \\
\hline A & $70 \%$ & $70 \%$ & $50 \%$ & $70 \%$ & $70 \%$ \\
B & $30 \%$ & $30 \%$ & $50 \%$ & $30 \%$ & $30 \%$ \\
\hline
\end{tabular}

$\ln \left(C_{t}\right)=\ln \left(C_{0} e^{-k t}\right)$,

where, $C_{t}$ represents the concentration of MP or PP at time $t, C_{0}$ represents the initial concentration and $k$ is the kinetic rate constant.

\subsubsection{Aerobic biodegradation}

To investigate aerobic degradation, $50 \mathrm{~mL}$ of the incubation medium (10\% activated sludge (v/v) in MMS and trace vitamins)was spiked with $1 \mathrm{mg} \mathrm{L}^{-1}$ or $10 \mathrm{mg} \mathrm{L}^{-1}$ of each paraben, then placed in a dark incubator shaker $\left(25^{\circ} \mathrm{C}, 150 \mathrm{rpm}\right)$. Aerobic conditions were maintained by sealing with a ventilative film. For aerobic experiments, preliminary experiments showed a rapid dissipation of selected parabens; thus, aerobic samples were collected at $0,5,10,20,30,60$, and $90 \mathrm{~min}$.

\subsubsection{Anaerobic biodegradation}

Anaerobic samples were prepared under the continuous flow of nitrogen. Briefly, parabens were spiked into $50 \mathrm{~mL}$ incubation medium $(10 \%$ activated sludge $(\mathrm{v} / \mathrm{v})$ in MMS and trace vitamins) in an anaerobic bottle in amounts sufficient to give 1 or $10 \mathrm{mg} \mathrm{L}^{-1}$ of each paraben. Following solvent evaporation, the bottles were sealed with rubber stoppers and plugged with aluminum rings to prevent air loss. For anaerobic experiments, samples were collected to detect the concentration of parabens at $0,2,4,6,9,18,24,48$, and $72 \mathrm{~h}$ based on the results of a preliminary experiment. The incubation medium was unamended with any of electron acceptors as the anaerobic control. Nitrate-reducing, sulfate-reducing and Fe-reducing conditions were achieved by amending with $20 \mathrm{mM}$ of $\mathrm{NaNO}_{3}, 20 \mathrm{mM}_{\text {of }} \mathrm{Na}_{2} \mathrm{SO}_{4}$, and $20 \mathrm{mM}$ of $\mathrm{Fe}$ (III) citrate, respectively. $1 \mathrm{mM}$ of $\mathrm{Na}_{2} \mathrm{~S}$ was added to three reducing treatments as reducing agent (Liu et al., 2011). All anaerobic bottles were incubated in the dark at $25^{\circ} \mathrm{C}$.

\subsection{Analytical methods}

To monitor the concentration of MP and PP, $2.0 \mathrm{~mL}$ samples were quickly moved from each experimental conical flask at the designated time and amended with $8 \mu \mathrm{L}$ of concentrated o-phosphoric acid to stop biodegradation (Oie et al., 2007; Larcher and Yargeau, 2011). Samples were then centrifuged at $10,000 \mathrm{rpm}$ for $10 \mathrm{~min}$ at $4{ }^{\circ} \mathrm{C}$ (Thermo Legend Micro 21), after which $1 \mathrm{~mL}$ of supernatant was passed through a
$0.22 \mu \mathrm{m}$ PVDF filter and transferred to an amber vial for HPLC analysis. Additionally, the samples prepared at sampling end points to determine the formation product of aerobic degradation were performed by gas chromatography-mass spectrometry (GC-MS) analysis (Agilent 78905975c), equipped with Agilent 19091S-433 HP-5MS capillary column (30 m $\times 250 \mathrm{~mm} \times 0.25 \mathrm{~mm}, 5 \%$ phenyl methyl silox) . The aerobic degradation product was extracted from the supernatant with an equal volume of $n$-hexane three times. The total extracts were collected and evaporated under fume cupboard, followed by redissolving in $n$ hexane. The oven temperature program was set from $60{ }^{\circ} \mathrm{C}$ at initial $2 \mathrm{~min}$, and then raised to $280{ }^{\circ} \mathrm{C}$ at $10^{\circ} \mathrm{C} \mathrm{min}{ }^{-1}$ followed by $2 \mathrm{~min}$ hold at $280^{\circ} \mathrm{C}$. Helium was used as the carrier gas at a flow rate of $1.0 \mathrm{~mL} \mathrm{~min}^{-1}$. Full scan mode was used with mass scan range of 40 $300 \mathrm{amu}$, and electron ionization mode was conducted at $70 \mathrm{eV}$ with $1 \mu \mathrm{L}$ of injection volume.

Determination of MP and PP was conducted using a Dionex Ultimate 3000 HPLC system equipped with a UV detector at a wavelength of $270 \mathrm{~nm}$ and a BDS HYPERSIL C18 column $(150 \times 2.1 \mathrm{~mm}, 3 \mu \mathrm{m})$. The mobile phase consisted of water: acetic acid $(A ; 100: 0.1, \mathrm{v} / \mathrm{v})$ and acetonitrile (B). The gradient is presented in Table 2 . The flow rate was set at $0.2 \mathrm{~mL} \mathrm{~min}^{-1}$ and an injection volume of $10 \mu \mathrm{L}$. The limit of detection (LOD) of the HPLC method for MP and PP was 5 and $2 \mu \mathrm{L} \mathrm{L}^{-1}$. Recoveries (\%) of the selected parabens in the experimental activated sludge were calculated from the data obtained by analysis of three replicates with MP and PP at $1 \mathrm{mg} \mathrm{L}^{-1}$. The recovery of the spiked concentration of MP and PP was $90 \pm 5 \%, 94 \pm 7 \%$, respectively.

\subsection{Statistical analyses}

Data were collected and analyzed using Microsoft Excel 2010 (Microsoft Corporation, Redmond, WA, USA). Significant difference was undertaken using SPSS version 15.0 (SPSS Inc., Chicago, IL, USA).

\section{Results and discussion}

\subsection{Aerobic biodegradation}

The biodegradation of MP and PP at two levels for the activated sludge as a percentage of the initial concentration across an interval of 90 min under aerobic conditions are presented in Fig. 1. The results revealed rapid biodegradation of MP and PP in non-sterile sludge, whereas little loss was observed in sterile sludge within $90 \mathrm{~min}(P<$ 0.05). Abiotic hydrolysis of MP and PP to $p$-hydroxybenzoic acid (4-HB) in liquid media has previously been reported (Valkova et al., 2001). In this study, the lack of an obvious mass loss of parent compound indicated that hydrolysis did not occur in the aerobic sterile samples, which may have been a result of the low initial concentration compared
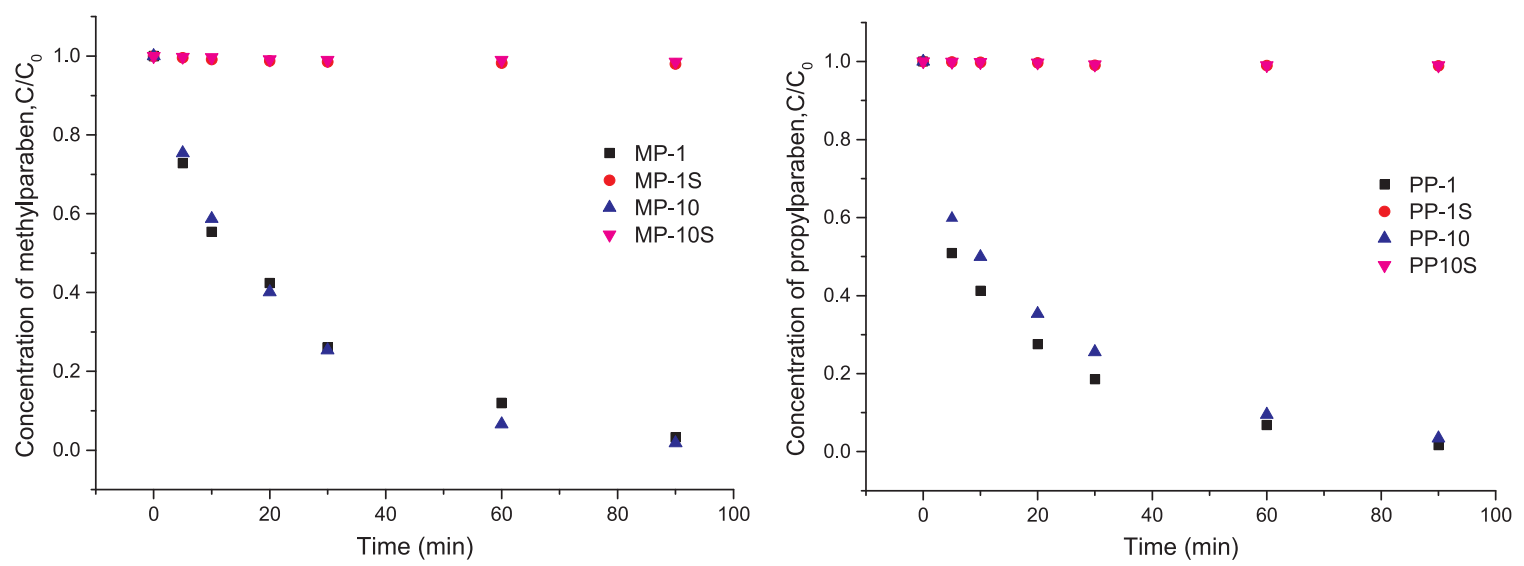

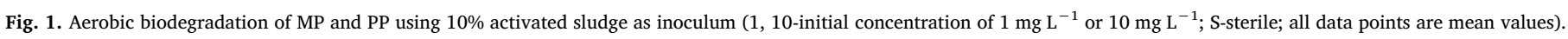


Table 3

Kinetic parameters for the biodegradation of MP and PP under aerobic conditions.

\begin{tabular}{llllll}
\hline Compound & Condition & $\begin{array}{l}\text { Concentration }(\mathrm{mg} \\
\left.\mathrm{L}^{-1}\right)\end{array}$ & $\begin{array}{l}k\left(\mathrm{mg} \mathrm{L}^{-1}\right. \\
\left.\mathrm{min}^{-1}\right)^{\mathrm{a}}\end{array}$ & $T_{1 / 2}(\mathrm{~min})^{\mathrm{b}}$ & $R^{2 \mathrm{c}}$ \\
\hline \multirow{2}{*}{$\mathrm{MP}$} & \multirow{2}{*}{ Aerobic } & 1 & 0.036 & 19.3 & 0.9911 \\
& & 10 & 0.044 & 15.8 & 0.9996 \\
PP & \multirow{2}{*}{ Aerobic } & 1 & 0.041 & 16.9 & 0.9827 \\
& & 10 & 0.035 & 19.8 & 0.9887 \\
\hline
\end{tabular}

${ }^{a}$ Kinetic rate constant $(k)$, which was calculated using the first-order reaction equation (mean value from duplicate experiments).

${ }^{\mathrm{b}}$ Half-life $\left(T_{1 / 2}\right)$, calculated as $(\ln 2) / k$.

${ }^{\mathrm{c}}$ Coefficient of correlation $(R)$, which represents the fitness of the experimental data.

with the levels in liquid culture (initial concentration of $500 \mathrm{mg} \mathrm{L}^{-1}$ of MP, or PP) in Valkova et al.'s study (2001). The aerobic degradation data for MP and PP were well explained by the first order kinetic model. The aerobic degradation kinetics parameters of MP and PP are listed in Table 3. The calculated kinetic rate constant $(k)$ of MP and PP showed the same dissipation trend under aerobic conditions. The $k$ values of MP and PP ranged from 0.036 to 0.044 , and $0.035-0.041$, respectively. The half-lives of MP and PP at initial concentrations of $1 \mathrm{mg} \mathrm{L}^{-1}$ or $10 \mathrm{mg} \mathrm{L}^{-1}$ were estimated to range between 15.8 and $19.8 \mathrm{~min}$, suggesting the parent compounds of MP and PP may quickly and largely biodegraded and eliminated from the WWTPs during the aerobic biological phase. The removal efficiencies of MP and PP over 90 min ranged from $96.7 \%$ to $98.2 \%$, and $96.6-98.3 \%$, respectively. The results were generally in accordance with those reported by González-Mariño et al. (2011), in their study, the test of aerobic biodegradability and stability in raw wastewater also showed that parabens degrade rapidly in real sewage. Notably, after $90 \mathrm{~min}$ of
Table 4

Kinetic parameters for the biodegradation of MP and PP under different anaerobic conditions.

\begin{tabular}{llllll}
\hline Compound & Condition & $\begin{array}{l}\text { Concentration } \\
\left(\mathrm{mg} \mathrm{L}^{-1}\right)\end{array}$ & $k\left(\mathrm{mg} \mathrm{L}^{-1} \mathrm{~h}^{-1}\right)^{\mathrm{a}}$ & $T_{1 / 2}(\mathrm{~h})^{\mathrm{b}}$ & $R^{2 \mathrm{c}}$ \\
\hline \multirow{2}{*}{$\mathrm{MP}$} & Anaerobic & 1 & 0.010 & 69.3 & 0.9909 \\
& control & 10 & 0.008 & 86.6 & 0.9889 \\
& Nitrate & 1 & 0.016 & 43.3 & 0.9921 \\
& reducing & 10 & 0.015 & 46.2 & 0.9919 \\
& Sulfate & 1 & 0.009 & 77.0 & 0.9906 \\
& reducing & 10 & 0.008 & 86.6 & 0.9834 \\
FP & Fe(III) & 1 & 0.009 & 77.0 & 0.9875 \\
& reducing & 10 & 0.007 & 99.0 & 0.9799 \\
& Anaerobic & 1 & 0.073 & 9.5 & 0.9992 \\
& control & 10 & 0.071 & 9.8 & 0.9977 \\
& Nitrate & 1 & 0.081 & 8.6 & 0.9968 \\
& reducing & 10 & 0.078 & 8.9 & 0.9923 \\
& Sulfate & 1 & 0.058 & 12.0 & 0.9991 \\
& reducing & 10 & 0.063 & 11.0 & 0.9869 \\
& Fe(III) & 1 & 0.072 & 9.6 & 0.9922 \\
& reducing & 10 & 0.077 & 9.0 & 0.9803 \\
& & & & & \\
\end{tabular}

${ }^{\text {a }}$ Kinetic rate constant $(k)$, which was calculated using the first-order reaction equation (mean value from duplicate experiments).

${ }^{\mathrm{b}}$ Half-life $\left(T_{1 / 2}\right)$, calculated as $(\ln 2) / k$.

${ }^{\mathrm{c}}$ Coefficient of correlation $(R)$, which represents the fitness of the experimental data.

incubation, trace residues of MP and PP were still detected in the activated sludge; hence, additional studies should be conducted to address their removal. Indeed, this might be the reason for the occurrence of these types of parabens in the following treatment phase and their subsequent spread to different environmental matrices (Jonkers et al., 2009; Hernández Leal et al., 2010).
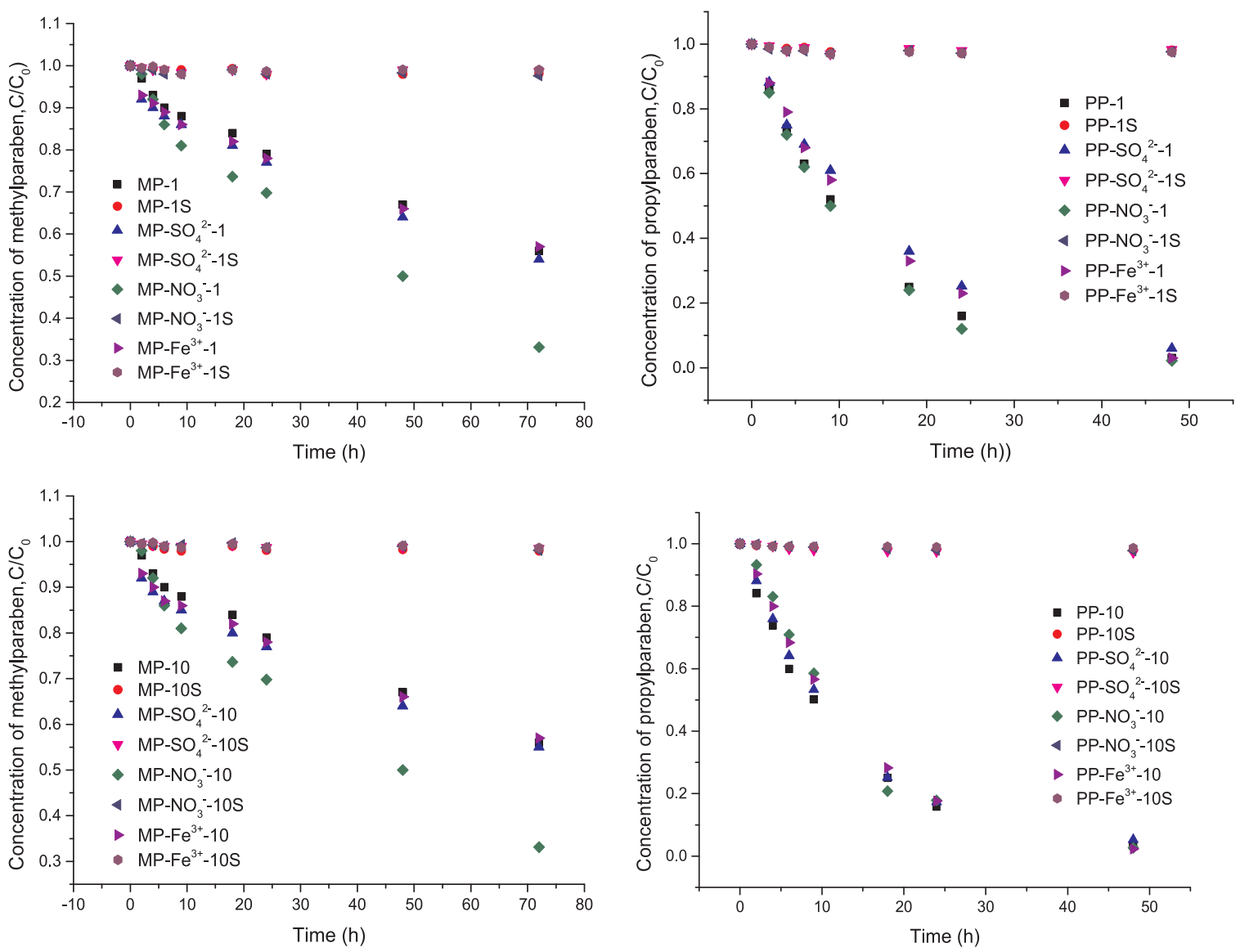

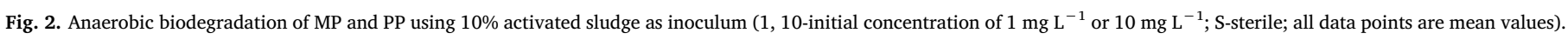


a

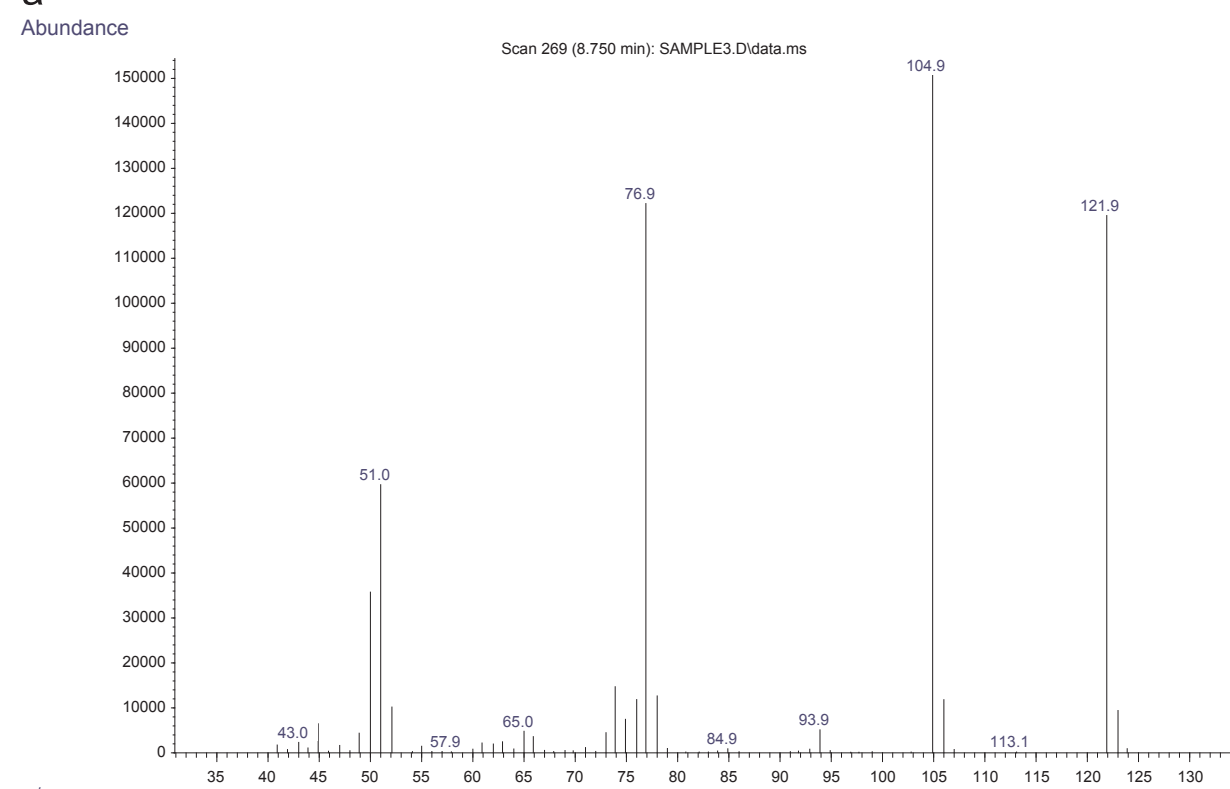

$\mathrm{m} / \mathrm{z-->}$

b

Abundance

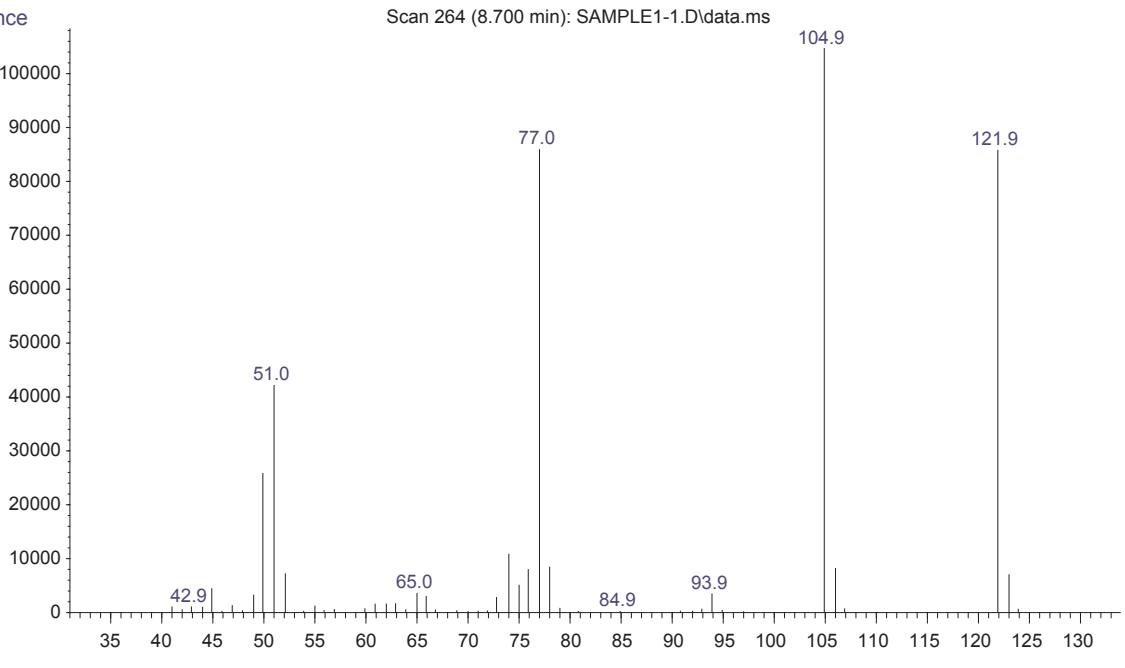

$\mathrm{m} / \mathrm{z-->}$

Fig. 3. Mass spectra of benzoic acid, a major biodegradation product, identified by GC-MS analysis under aerobic conditions for MP(a) and PP(b), respectively.

\subsection{Anaerobic biodegradation}

As shown in Fig. 2, comparatively slow biodegradation of MP and $\mathrm{PP}$ over the incubation period ( $72 \mathrm{~h}$ for MP, $48 \mathrm{~h}$ for PP) was observed at both concentrations under different anaerobic reducing conditions, whereas little loss was observed from sterile activated sludge within $72 \mathrm{~h}$ for MP and $48 \mathrm{~h}$ for PP $(P<0.05)$. Nitrate-reducing, sulfatereducing and Fe-reducing conditions commonly occur in anaerobic environments (Liu et al., 2011); however, among these three reducing conditions, only nitrate addition significantly accelerated the anaerobic biodegradation of MP or PP, when compared to that of the anaerobic control $(P<0.05)$. These findings indicate that the biodegradation of these two compounds was relatively slow in the anoxic conditions compared to aerobic degradation. Similar to the aerobic sterile controls, there was no obvious loss of mass of the parent compounds, indicating that hydrolysis did not occur in the anaerobic sterile samples as well. The anaerobic degradation data for MP and PP also fit the first order kinetic model well. The anaerobic degradation kinetics parameters of MP and PP are listed in Table 4. The removal efficiencies of were estimated to range from $43.2 \%$ to $70.1 \%$ for MP over $72 \mathrm{~h}$, and $94.1-$ $97.8 \%$ for PP over 48 h, respectively. However, Li et al. (2015) and Yu et al. (2011) adopted mass balance to calculate the overall removal efficiency, and their mass flow results showed that the high mass change in the anaerobic tank suggested that parabens were mainly biodegraded in this unit, this may be due to the theoretical calculation only based on the concentration difference between each treatment unit, which may not accurately describe the actual biodegradation process; additionally, in their study, the sampling of wastewater was just conducted on a separate weekday, not for longer consecutive days, this also should be addressed. In this study, half-lives of MP and PP under anaerobic conditions have been estimated to range between 8.6 and $99.0 \mathrm{~h}$, showing that parabens with longer alkyl chains (PP) underwent faster degradation than those with short alkyl chains (MP) under anaerobic conditions, while no difference in the rate of degradation was observed under aerobic conditions. Therefore, based on the calculated half-lives of MP and PP from anaerobic biodegradation test, we further speculate that elimination of parabens does not occur in the anaerobic phase of actual WWTPs if a sufficient hydraulic retention 


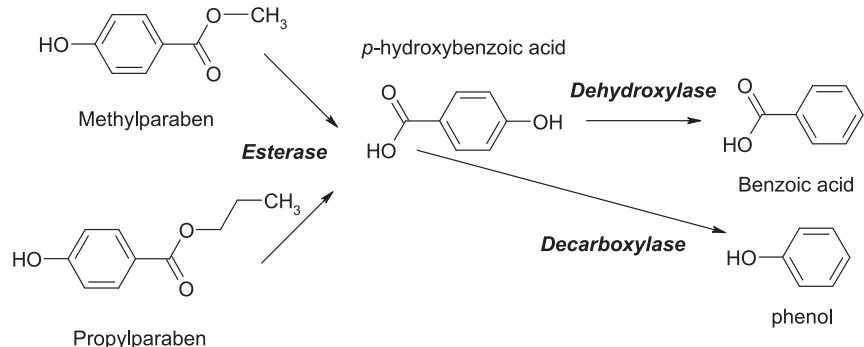

Fig. 4. Possible methylparaben and propylparaben pathway of degradation by aerobic mixed microbes (Valkova et al., 2001; Amin et al., 2010).

time is not achieved.

\subsection{Possible biodegradation products of $M P$ and $P P$}

In the case of aerobic incubation (initial concentration of $10 \mathrm{mg} \mathrm{L}^{-1}$ ), biodegradation products of MP and PP were tentatively investigated by GC-MS analysis. A significant peak with a retention time $8.70-8.75 \mathrm{~min}$ appeared in the $n$-hexane extract of aerobic incubation samples. The $\mathrm{m} / \mathrm{z}$ value of 121.9 of the peak was clearly extracted (Fig. 3) and identified as benzoic acid (BA) by comparison to a GC-MS library, suggesting that biodegradation of the selected parabens occurred via cleavage of a series of carbon bonds by mixed aerobic microbes. Benzoic acid is recognized as a nonspecific marker of parabens (Ye et al., 2006). In the present study, p-hydroxybenzoic acid, the reported common metabolite of all paraben esters (Amin et al., 2010; Wang et al., 2015; Moos et al., 2015; Wang and Kannan, 2016), was not detected in the samples upon GC-MS analysis, while we did not detect the metabolite in the MP and PP controls as well. Therefore, it is possible that $p$-hydroxybenzoic acid was further oxidized to benzoic acid by mixed microbes during the rapid aerobic degradation process. Based on a study conducted by Valkova et al. (2001), paraben degradation originally occurred through hydrolysis of the ester bond to produce $p$-hydroxybenzoic acid via esterase activity, followed by a decarboxylation step under aerobic conditions, and phenol was reported as one of the major products (Amin et al., 2010). A possible MP and PP degradation pathway by aerobic mixed microbes based on the results of previous studies combined with those of our study is shown in Fig. 4. However, additional research is needed to clearly and accurately interpret the mechanism of biodegradation. In addition, these above results demonstrate that the ability of mixed microbes to degrade parabens does not precisely reflect the roles of individual microorganisms; thus, further research to evaluate individual microorganisms isolated from WWTPs should also be initiated.

\section{Conclusions}

The results of the biodegradation experiments demonstrated that microbes could readily degrade MP and PP under aerobic conditions, with half-lives of less than $20 \mathrm{~min}$ for both compounds, regardless of their original concentration. However, comparatively longer period of time was needed for anaerobic degradation. The shortest biodegradation half-lives for MP and PP of $43.3 \mathrm{~h}$ and $8.6 \mathrm{~h}$, respectively, were both observed under nitrate reducing conditions. Anaerobic biodegradation tests also clearly demonstrated that paraben species with longer alkyl chains (e.g., PP) underwent faster degradation than those with shorter alkyl chains (e.g., MP). Benzoic acid was identified as the biodegradation product of MP and PP under aerobic conditions. These results suggest that biodegradation of parabens would be an important removal mechanism in WWTPs, whereas trace concentrations of parabens were still detected in the final samples of activated sludge, and additional work to optimize biological removal techniques is still needed.

\section{Acknowledgments}

This research was funded by Grants from the Natural Science Foundation of the Anhui Provincial Education Department (KJ2014A216), Anhui Provincial Natural Science Foundation (1508085QD72), National Science Foundation of China (31370503, 41573102) and Youth Innovation Promotion Association CAS (2016280).

\section{References}

Albero, B., Pérez, R.A., Sánchez-Brunete, C., Tadeo, J.L., 2012. Occurrence and analysis of parabens in municipal sewage sludge from wastewater treatment plants in Madrid (Spain). J. Hazard. Mater. 239, 48-55.

Amin, A., Chauhan, S., Dare, M., Bansal, A.K., 2010. Degradation of parabens by Pseudomonas beteli and Burkholderia latens. Eur. J. Pharm. Biopharm. 75, 206-212.

Andersen, F.A., 2008. Final amended report on the safety assessment of methylparaben, ethylparaben, propylparaben, isopropylparaben, butylparaben, isobutylparaben, and benzylparaben as used in cosmetic products. Int. J. Toxicol. 27, 1-82.

Błędzka, D., Gromadzińska, J., Wąsowicz, W., 2014. Parabens. From environmental studies to human health. Environ. Int. 67, 27-42.

Canosa, P., Rodríguez, I., Rubi, E., Negreira, N., Cela, R., 2006. Formation of halogenated by-products of parabens in chlorinated water. Anal. Chim. Acta 575 (1), 106-113.

Darbre, P.D., Charles, A.K., 2010. Environmental oestrogens and breast cancer: evidence for combined involvement of dietary, household and cosmetic xenoestrogens. Anticancer Res. 30, 815-827.

Evgenidou, E.N., Konstantinou, I.K., Lambropoulou, D.A., 2015. Occurrence and removal of transformation products of PPCPs and illicit drugs in wastewaters: a review. Sci. Total. Environ. 505, 905-926.

González-Mariño, I., Quintana, J.B., Rodríguez, I., Cela, R., 2011. Evaluation of the occurrence and biodegradation of parabens and halogenated by-products in wastewater by accurate-mass liquid chromatography-quadrupole-time-of-flight-mass spectrometry (LC-QTOF-MS). Water Res. 45, 6770-6780.

Gorga, M., Insa, S., Petrovic, M., Barceló, D., 2015. Occurrence and spatial distribution of EDCs and related compounds in waters and sediments of Iberian rivers. Sci. Total. Environ. 503, 69-86.

Guo, Y., Wang, L., Kannan, K., 2014. Phthalates and parabens in personal care products from China: concentrations and human exposure. Arch. Environ. Con. Tox. 66, $113-119$.

Haman, C., Dauchy, X., Rosin, C., Munoz, J.F., 2015. Occurrence, fate and behavior of parabens in aquatic environments: a review. Water Res. 68, 1-11.

Hernández Leal, L., Vieno, N., Temmink, H., Zeeman, G., Buisman, C.J., 2010. Occurrence of xenobiotics in gray water and removal in three biological treatment systems. Environ. Sci. Technol. 44, 6835-6842.

Jonkers, N., Kohler, H.P.E., Dammshäuser, A., Giger, W., 2009. Mass flows of endocrine disruptors in the Glatt River during varying weather conditions. Environ. Pollut. 157, 714-723.

Larcher, S., Yargeau, V., 2011. Biodegradation of sulfamethoxazole by individual and mixed bacteria. Appl. Microbiol. Biotechnol. 91, 211-218.

Li, W., Shi, Y., Gao, L., Liu, J., Cai, Y., 2015. Occurrence, fate and risk assessment of parabens and their chlorinated derivatives in an advanced wastewater treatment plant. J. Hazard. Mater. 300, 29-38.

Liao, C., Lee, S., Moon, H.B., Yamashita, N., Kannan, K., 2013. Parabens in sediment and sewage sludge from the United States, Japan, and Korea: spatial distribution and temporal trends. Environ. Sci. Technol. 47, 10895-10902.

Liu, Y.S., Ying, G.G., Shareef, A., Kookana, R.S., 2011. Biodegradation of three selected benzotriazoles under aerobic and anaerobic conditions. Water Res. 45, 5005-5014.

Lozada, M., Itria, R.F., Figuerola, E.L., Babay, P.A., Gettar, R.T., De Tullio, L.A., Erijman, L., 2004. Bacterial community shifts in nonylphenol polyethoxylates-enriched activated sludge. Water Res. 38, 2077-2086.

Ma, W.L., Zhao, X., Lin, Z.Y., Mohammed, M.O., Zhang, Z.F., Liu, L.Y., Li, Y.F., 2016. A survey of parabens in commercial pharmaceuticals from China and its implications for human exposure. Environ. Int. 95, 30-35.

Madsen, T., Boyd, H.B., Nylén, D., Pedersen, A.R., Petersen, G.I., Simonsen, F., 2001. Environmental and health assessment of substances in household detergents and cosmetic detergent products. Environ. Proj. 615, 221.

Matamoros, V., Rodríguez, Y., Albaigés, J., 2016. A comparative assessment of intensive and extensive wastewater treatment technologies for removing emerging contaminants in small communities. Water Res. 88, 777-785.

Meeker, J.D., Yang, T., Ye, X., Calafat, A.M., Hauser, R., 2011. Urinary concentrations of parabens and serum hormone levels, semen quality parameters, and sperm DNA damage. Environ. Health Perspect. 119, 252.

Molins-Delgado, D., Díaz-Cruz, M.S., Barceló, D., 2016. Ecological risk assessment associated to the removal of endocrine-disrupting parabens and benzophenone- 4 in wastewater treatment. J. Hazard. Mater. 310, 143-151.

Moos, R.K., Angerer, J., Dierkes, G., Brüning, T., Koch, H.M., 2015. Metabolism and elimination of methyl, iso-and n-butyl paraben in human urine after single oral dosage. Arch. Toxicol., 1-11.

Oie, C.S., Albaugh, C.E., Peyton, B.M., 2007. Benzoate and salicylate degradation by Halomonas campisalis, an alkaliphilic and moderately halophilic microorganism. Water Res. 41, 1235-1242.

Petala, A., Frontistis, Z., Antonopoulou, M., Konstantinou, I., Kondarides, D.I., 
Mantzavinos, D., 2015. Kinetics of ethyl paraben degradation by simulated solar radiation in the presence of $\mathrm{N}$-doped $\mathrm{TiO}_{2}$ catalysts. Water Res. 81, 157-166.

Schlumpf, M., Kypke, K., Wittassek, M., Angerer, J., Mascher, H., Mascher, D.

Lichtensteiger, W., 2010. Exposure patterns of UV filters, fragrances, parabens,

phthalates, organochlor pesticides, PBDEs, and PCBs in human milk: correlation of UV filters with use of cosmetics. Chemosphere 81, 1171-1183.

Sun, Q., Li, M., Ma, C., Chen, X., Xie, X., Yu, C.P., 2016. Seasonal and spatial variations of PPCP occurrence, removal and mass loading in three wastewater treatment plants located in different urbanization areas in Xiamen, China. Environ. Pollut. 208, 371-381.

Valkova, N., Lépine, F., Valeanu, L., Dupont, M., Labrie, L., Bisaillon, J.G., Villemur, R., 2001. Hydrolysis of 4-hydroxybenzoic acid esters (parabens) and their aerobic transformation into phenol by the resistant Enterobacter cloacae strain EM. Appl, Environ. Mocrobiol. 67, 2404-2409.

Wang, L., Wu, Y., Zhang, W., Kannan, K., 2013. Characteristic profiles of urinary pHydroxybenzoic acid and its esters (parabens) in children and adults from the U.S. and China. Environ. Sci. Technol. 47, 2069-2076.

Wang, L., Liu, T., Liu, F., Zhang, J., Wu, Y., Sun, H., 2015. Occurrence and profile characteristics of the pesticide Imidacloprid, preservative Parabens, and their metabolites in human urine from rural and urban china. Environ. Sci. Technol. 49, 14633-14640.

Wang, W., Kannan, K., 2016. Fate of parabens and their metabolites in two wastewater treatment plants in New York state, United States. Environ. Sci. Technol. 50, 1174-1181.

Wu, Y., Yu, C.P., Yue, M., Liu, S.P., Yang, X.Y., 2016. Occurrence of selected PPCPs and sulfonamide resistance genes associated with heavy metals pollution in surface sediments from Chao Lake, China. Environ. Earth Sci. 75, 1-8.

Xue, J., Sasaki, N., Elangovan, M., Diamond, G., Kannan, K., 2015. Elevated Accumulation of Parabens and their Metabolites in Marine Mammals from the United States Coastal Waters. Environ. Sci. Technol. 49, 12071-12079.

Yang, Y., McCarty, P.L., 1998. Competition for hydrogen within a chlorinated solvent dehalogenating anaerobic mixed culture. Environ. Sci. Technol. 32, 3591-3597.

Ye, X., Bishop, A.M., Reidy, J.A., Needham, L.L., Calafat, A.M., 2006. Parabens as urinary biomarkers of exposure in humans. Environ. Health Perspect., 1843-1846.

Yu, Y., Huang, Q., Wang, Z., Zhang, K., Tang, C., Cui, J., Peng, X., 2011. Occurrence and behavior of pharmaceuticals, steroid hormones, and endocrine-disrupting personal care products in wastewater and the recipient river water of the Pearl River Delta, South China. J. Environ. Monit. 13, 871-878. 